Check for updates

Cite this: RSC Adv., 2019, 9, 32348

\title{
The $\beta$-cyclodextrin-modified nanosized ZSM-5 zeolite as a carrier for curcumin
}

\author{
Shahin Amani, Amir Bagheri Garmarudi, (DD* Niloofar Rahmani \\ and Mohammadreza Khanmohammadi
}

\begin{abstract}
Herein, the nanosized ZSM- 5 zeolite was synthesized based on a fractional factorial experimental design by a hydrothermal method to study the optimum conditions for the synthesis and formation of the ZSM-5 zeolite by employing different conditions. The samples were synthesized without any organic template, and different conditions, such as the molar composition of the synthesis gel and reaction time, were applied in a wide range. Then, the samples were analysed by $\mathrm{X}$-ray diffraction to investigate the formation of the zeolite ZSM-5, and the results were compared to obtain the optimum conditions for its synthesis. The obtained samples were characterized by SEM, FTIR spectroscopy and TGA. Then, the functionalization of nano zeolite ZSM- 5 crystals with $\beta$-cyclodextrin ( $\beta$-CD) was investigated. The zeolite surface was first functionalized with amino groups using an amino alkoxysilane. Then, toluene diisocyanate was reacted with the amino-terminated ZSM-5 zeolite crystals and used for the incorporation of $\beta-C D$ via its remaining isocyanate groups. After this, a drug delivery system (DDS) was prepared based on the cyclodextrin-modified zeolite with the curcumin anticancer drug, and its formation was studied under experimental conditions. The results of in vitro studies show that this drug delivery system has better characteristics than free curcumin in terms of stability and anti-proliferative and anti-inflammatory effects.
\end{abstract}

Received 24th June 2019
Accepted 13th August 2019

DOI: $10.1039 /$ c9ra04739e

rsc.li/rsc-advances the pores and channels enable the encapsulation of small molecules. Zeolites have many applications including industrial, environmental, and biotechnological. Furthermore, numerous examples of medical applications of zeolites, such as in the immobilization of enzymes for biological sensing, ${ }^{6}$ the imaging of magnetic resonance, ${ }^{7-11}$ the treatment of wounds, and as a drug delivery system (DDS), ${ }^{12-15}$ have been reported. The most famous zeolite with an MFI structure is ZSM-5. ZSM-5 zeolites are widely used as catalysts, particularly in acid catalytic reactions, due to the special structure and size of their channels, stable structure and wide ranges of the silicon to aluminum ratio; moreover, due to the presence of aluminum, the framework is negatively charged, which endows the zeolite with ion exchange properties; this allows the absorption and release of charged molecules. Modification of zeolites for their compatibility as potential drug carriers improves their performance. A zeolite modified with cyclodextrin can play the role of two hosts for guest molecules. In this study, we fabricated ZSM-5 zeolites for a drug delivery system by a hydrothermal method. The structure, morphology, biocompatibility, and drug delivery properties of the ZSM-5 zeolites were investigated; moreover, we investigated the use of cyclodextrin (CD) host-guest chemistry as a model system for the functionalization of the zeolite surface. In addition, one of the main features of cyclodextrin molecules is the formation of an inclusion complex with guest hydrophobic molecules in their nano-holes. Cyclodextrin has a hydrophilic cavity in the outer part and a hydrophobic cavity in the 
inner part. These properties are responsible for its solubility in water and ability to encapsulate hydrophobic parts in its cavities; moreover, the binding of "guest" molecules in the inclusion complexes of cyclodextrin in an aqueous environment is the basis for its pharmaceutical applications. However, more studies are needed to understand the basics of the interaction of cyclodextrin-modified zeolite with a drug molecule such that the loading and the release of the drug can be significantly improved. In this study, curcumin was used as a model drug. Curcumin is a polyphenol yellow compound, which has a low molecular weight and is derived from the rhizome of the plant Curcuma longa that has a wide range of biological applications such as in the treatment of cancer; furthermore, curcumin is widely used as an anti-inflammatory, antimicrobial, anti-oxidant, and anti-parasitic drug as well as a drug against the human immunodeficiency virus. ${ }^{\mathbf{1 6 - 2 0}}$ Despite all these wonderful medicinal properties, curcumin has low solubility in aqueous solutions and undergoes rapid degradation at physiological $\mathrm{pH}$; this leads to its poor bioavailability and low medicinal properties that significantly hinder its effectiveness in the body. ${ }^{\mathbf{2 1 , 2 2}}$ In this regard, various formulations have been created based on the encapsulation of curcumin in the nanoparticles or nano gels of polymers, surfactants, proteins, and phospholipids. ${ }^{23-30}$ These systems not only improve the drug solubility and stability but also provide medicines for cancer cells in their active form. In this study, beta-cyclodextrin has been chosen for the encapsulation of curcumin because it is a semi-natural product with very low toxicity that increases the drug delivery through biological membranes; ${ }^{31}$ furthermore, ZSM-5 created by the template-free technique has the advantage of a more sustainable synthetic route, which avoids the use of toxic and expensive organic templates and the formation of harmful gases by the calcination of organic templates at high temperatures. ${ }^{32-34}$ Eventually, in this context, we have reported the preparation of a drug delivery system (DDS) based on the cyclodextrin-modified ZSM-5 zeolite using the curcumin anticancer drug and demonstrated its efficiency against cancer cells (Fig. 1).

\section{Experimental}

\section{Preparation of nanosized, template-free ZSM-5 zeolite}

Template-free ZSM-5 was synthesized from a synthesis solution prepared by dissolving sodium hydroxide $(\mathrm{NaOH} \geq 96.0 \mathrm{wt} \%)$ and sodium aluminate $\left(\mathrm{NaAlO}_{2}\right)$ in deionized water. The mixture was thoroughly mixed, and tetraethylorthosilicate (TEOS, $\geq 99 \%$, Aldrich) was slowly added to the abovementioned solution under stirring at a high speed. Then, the abovementioned synthesis solution was aged for $12 \mathrm{~h}$ at room temperature; after this, it was transferred to a Teflon-lined stainless steel autoclave and hydrothermally treated in an oven at $180{ }^{\circ} \mathrm{C}$. After the hydrothermal

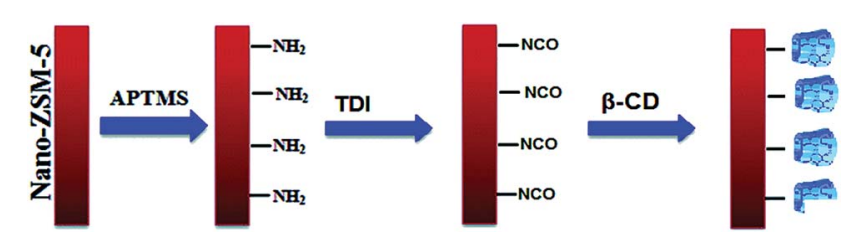

Fig. 1 Schematic of the modification of the ZSM-5 zeolite with $\beta-C D$. treatment, the products were thoroughly washed with deionized water until the $\mathrm{pH}$ value of the washing water reached 7-8 and then dried at room temperature.

\section{Experimental design}

Experimental factors, levels and response. Table 1 shows an estimate of the ZSM-5 zeolite synthesis conditions without template. Usually, the reactant materials used (tetraethyl orthosilicate, sodium aluminate, sodium hydroxide), their order of mixing, and the crystallization temperature were not significantly changed. However, the optimal gel composition presented in Table 1 was significantly different. ${ }^{35}$

Therefore, the primary gel composition was evaluated in this study. The minimum and maximum factors examined herein are reported in the following table. ${ }^{36}$

The factors were the molar ratios $\mathrm{Na}_{2} \mathrm{O} / \mathrm{SiO}_{2}\left(\mathrm{X}_{1}\right), \mathrm{SiO}_{2} / \mathrm{Al}_{2} \mathrm{O}_{3}$ $\left(\mathrm{X}_{2}\right)$, and $\mathrm{H}_{2} \mathrm{O} / \mathrm{SiO}_{2}\left(\mathrm{X}_{3}\right)$ and aging time $\left(\mathrm{X}_{4}\right)$. Each factor was set at two different levels, i.e. low and high, which were coded as $(-1)$ and $(+1)$, respectively. Table 2 shows these factors and levels.

Experimental design procedure. Based on the preliminary design of experiments, 16 nanosized zeolite synthesis processes were designed. Table 3 shows the detailed processes of the synthesis, and the coded levels $( \pm 1)$ are presented in the columns 2-5. The last column shows the response measured $Y$ for each run, and it was related to the relative crystallinity of the ZSM-5 samples and consequently to the efficiency of the formation of crystalline nano zeolite. The percent crystallinity of each sample was determined from the ratio of the height of the most intensive $2 \theta$ reflection in the XRD pattern $\left(23.1^{\circ}, 2 \theta\right)$ to the height of the $2 \theta$ reflection of a highly crystalline sample as reported in ref. 39. The running order was randomized to minimize probable systematic errors. It was important to determine the optimal gel composition as well as the zeolite formation efficiency. To obtain this information, a mathematical model was used, which created a relationship between the response $(Y)$ and the factors $\mathrm{X}_{1}, \mathrm{X}_{2}, \mathrm{X}_{3}$, and $\mathrm{X}_{4}$. In this model, all the main effects and interactions of the factors were considered. This model is a polynomial model as shown in the following equation:

$$
\begin{aligned}
Y=\beta_{0} & +\beta_{1} \mathrm{X}_{1}+\beta_{2} \mathrm{X}_{2}+\ldots+\beta_{K} \mathrm{X}_{K}+\beta_{11} \mathrm{X}_{1}^{2}+\ldots+\beta_{K K} \mathrm{X}_{K}^{2} \\
& +\beta_{12} \mathrm{X}_{1} \mathrm{X}_{2}+\beta_{13} \mathrm{X}_{1} \mathrm{X}_{3}+\ldots+\beta_{K-1} \mathrm{X}_{K-1} \mathrm{X}_{K}+\varepsilon
\end{aligned}
$$

where $Y$ is the response, $\beta_{0}$ is a constant, $\beta_{1}, \beta_{2}, \beta_{3}$ and $\beta_{4}$ are coefficients of the coded factors $\mathrm{X}_{1}, \mathrm{X}_{2}, \mathrm{X}_{3}$, and $\mathrm{X}_{4}$, respectively; $\beta_{12}, \beta_{13}$ and $\beta_{14}$ are the coefficients of the interaction effects between two factors.

Table 1 Synthesis conditions of the ZSM-5 zeolite

\begin{tabular}{lll}
\hline Reference & Molar ratio of gel compositions & Time (h) \\
\hline 37 & $7.2 \mathrm{Na}_{2} \mathrm{O}: 60 \mathrm{SiO}_{2}: 3 \mathrm{Al}_{2} \mathrm{O}_{3}: 1500 \mathrm{H}_{2} \mathrm{O}$ & 24 \\
38 & $12 \mathrm{Na}_{2} \mathrm{O}: 60 \mathrm{SiO}_{2}: \mathrm{Al}_{2} \mathrm{O}_{3}: 3180 \mathrm{H}_{2} \mathrm{O}$ & 72 \\
& $12 \mathrm{Na}_{2} \mathrm{O}: 100 \mathrm{SiO}_{2}: 5 \mathrm{Al}_{2} \mathrm{O}_{3}: 2500 \mathrm{H}_{2} \mathrm{O}$ & 24
\end{tabular}


Table 2 Experimental factors and levels investigated in the experiment

\begin{tabular}{lll}
\hline & Parameter values & \\
\cline { 2 - 3 } Factors & Low level $(-1)$ & High level $(+1)$ \\
\hline $\mathrm{X}_{1}: \mathrm{Na}_{2} \mathrm{O} / \mathrm{SiO}_{2}$ & 0.12 & 0.2 \\
$\mathrm{X}_{2}: \mathrm{SiO}_{2} / \mathrm{Al}_{2} \mathrm{O}_{3}$ & 20 & 60 \\
$\mathrm{X}_{3}: \mathrm{H}_{2} \mathrm{O} / \mathrm{SiO}_{2}$ & 25 & 53 \\
$\mathrm{X}_{4}:$ aging time & 24 & 72
\end{tabular}

Table 3 Fractional factorial experiment design

\begin{tabular}{lrrrrc}
\hline Run & $\mathrm{X}_{1}$ & $\mathrm{X}_{2}$ & $\mathrm{X}_{3}$ & $\mathrm{X}_{4}$ & $Y(\%)$ \\
\hline 1 & 1 & -1 & 1 & -1 & 53.5 \\
2 & -1 & 1 & 1 & -1 & 51.2 \\
3 & 1 & -1 & -1 & 1 & 10 \\
4 & -1 & 1 & 1 & -1 & 51.2 \\
5 & 1 & 1 & 1 & 1 & 100 \\
6 & -1 & -1 & -1 & -1 & 31.9 \\
7 & -1 & -1 & 1 & 1 & 45.6 \\
8 & 1 & -1 & 1 & -1 & 53.5 \\
9 & -1 & 1 & -1 & 1 & 66.3 \\
10 & 1 & 1 & 1 & 1 & 100 \\
11 & -1 & -1 & 1 & 1 & 45.6 \\
12 & -1 & -1 & -1 & -1 & 31.9 \\
13 & -1 & 1 & -1 & 1 & 66.3 \\
14 & 1 & 1 & -1 & -1 & 41.3 \\
15 & 1 & 1 & -1 & -1 & 41.3 \\
16 & 1 & -1 & -1 & 1 & 10 \\
& & & & &
\end{tabular}

Functionalization of the ZSM-5 zeolite with $\boldsymbol{\beta}$-CD (synthesis of hybrid materials). Cyclodextrin-modified zeolite was prepared by the following method: at first, zeolite ZSM- 5 crystals (100 mg) were dispersed in toluene $(10 \mathrm{~mL})$ followed by the addition of $100 \mu \mathrm{L}$ of 3-aminopropyl trimethoxysilane (APTMS) and sonication for $2 \mathrm{~h}$. Then, the mixture was centrifuged with toluene (two times) and $\mathrm{EtOH}$ (three times) to remove excess unreacted alkoxysilane. In the next step, the ZSM-5 zeolite crystals functionalized with the amino groups (the amino terminal) were redispersed in $0.05 \mathrm{M}$ toluene diisocyanate (TDI) in $\mathrm{EtOH}$ for $2 \mathrm{~h}$ at $40^{\circ} \mathrm{C}$. Then, the mixture was centrifuged with EtOH (three times). The zeolite crystals functionalized with cyanate groups were subsequently redispersed in an aqueous solution of $\beta$-CD $(0.4 \mathrm{M})$, and the reaction was performed for $2 \mathrm{~h}$ $\left(40{ }^{\circ} \mathrm{C}\right)$.

Finally, the ZSM-5 zeolite crystals modified with betacyclodextrin were washed with water and dried at room temperature. $^{40}$

Preparation of the inclusion complex of $\beta$-cyclodextrinmodified zeolite and curcumin. $\beta$-Cyclodextrin-modified zeolite (CDZ) inclusion complexes were prepared following a methanol reflux method. ${ }^{41}$ Curcumin and carriers at a certain amount were dissolved in methanol and water, respectively. The curcumin solution was slowly added to the carrier aqueous solution under stirring at a high speed. The mixture was refluxed for 4 hours at $70{ }^{\circ} \mathrm{C}$ under vigorous shaking. Methanol was removed from the mixture by stirring the mixture for $1 \mathrm{~h}$ at $70{ }^{\circ} \mathrm{C}$ without reflux, followed by rotary evaporation. The resulting aqueous mixture was cooled down to room temperature before freeze drying to produce an amorphous powder of the complex of CDZ-CUR (Fig. 2).

In vitro drug release. Typically, $15 \mathrm{mg}$ of the CDZ-CUR complex was dispersed in $5 \mathrm{~mL}$ phosphate buffer $(0.01 \mathrm{M}$ PBS, $\mathrm{pH}=7.4$ and $\mathrm{pH}=5.5$ ). This suspension was incubated at $37^{\circ} \mathrm{C}$ under intense shaking. To measure the concentration of the drug in the phosphate buffer during delivery, at regular intervals, the sample ( $3 \mathrm{~mL}$ ) was withdrawn after $0.5,1,2,3,4,5,6,7$, ..., $24 \mathrm{~h}$ and replaced with $3 \mathrm{~mL}$ fresh buffer solution; moreover, its absorption was measured at the wavelength of $427 \mathrm{~nm}$ by a UV-Vis spectrophotometer and the efficiency of drug release was calculated using the following equation:

$$
\begin{aligned}
& \% \text { CUR release }=(\text { released curcumin } / \mathrm{CDZ}-\mathrm{CUR} \text { inclusion } \\
& \text { complex) } \times 100 \text {. }
\end{aligned}
$$

\section{Results and discussion}

\section{Characterization of the ZSM-5 zeolite}

A series of tests were performed with regard to the fractional factorial design. The response $Y$ varied between $100 \%$ and $10 \%$. Higher values of $Y$ were obtained during the Run 5 and 9. Moreover, the Run 5 had the highest yield of zeolite.

\section{Analysis of variance}

Analysis of variance was used to analyze the effects of experimental factors on the efficiency of ZSM-5. Results of the analysis of variance are shown in Table 4 . In this table, the amount of $p$ determines which factors are more effective. If the $p$ value is less than 0.05 , the factors are effective. As shown in Table 4, the main effects and two-way interaction terms are important to the process of ZSM-5 synthesis $(p<0.05)$. Fig. 3 shows the Pareto chart of standardized effects, which demonstrates that all the variables can be important factors. The order of the importance of factors is $\mathrm{SiO}_{2} / \mathrm{Al}_{2} \mathrm{O}_{3}>\mathrm{H}_{2} \mathrm{O} / \mathrm{SiO}_{2}>$ aging time $\gg \mathrm{Na}_{2} \mathrm{O} / \mathrm{SiO}_{2}$. Interactions between different variables have a significant effect on the zeolite synthesis. The two-way interactions are $\mathrm{X}_{1} \mathrm{X}_{2}$, $\mathrm{X}_{1} \mathrm{X}_{3}$, and $\mathrm{X}_{1} \mathrm{X}_{4}$. The most important two-way interaction variable is $\mathrm{X}_{1} \mathrm{X}_{3}$. Note that although $\mathrm{X}_{1}$ has a slight effect on the response, its interaction with $\mathrm{X}_{3}$ is important.

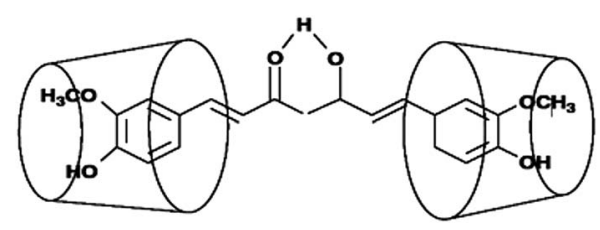

Fig. 2 Schematic of the structures of cyclodextrin-curcumin (CDCUR) inclusion complexes. 
Table 4 Analysis of variance for $Y$

\begin{tabular}{lrrrrrr}
\hline Source & $\mathrm{DF}^{a}$ & Seq SS $^{b}$ & Adj SS $^{c}$ & Adj MS $^{d}$ & \multicolumn{1}{c}{$\mathrm{F}^{e}$} & $\mathrm{P}^{f}$ \\
\hline Main effects & 4 & 6453.2 & 5756.7 & 1439.2 & 12.36 & 0.002 \\
2-Way interactions & 3 & 2219.6 & 2219.6 & 739.9 & 6.36 & 0.016 \\
Residual error & 8 & 931.2 & 931.2 & 116.4 & & \\
Lack of fit & 1 & 931.2 & 931.2 & 931.2 & & \\
Pure error & 7 & 0.0 & 0.0 & 0.0 & & \\
Total & 15 & 9604.1 & & & &
\end{tabular}

${ }^{a}$ Degree of freedom. ${ }^{b}$ Sequential sum of squares. ${ }^{c}$ Adjusted sum of squares. ${ }^{d}$ Adjusted mean of squares. ${ }^{e} F$-Test. ${ }^{f} P$-Value.

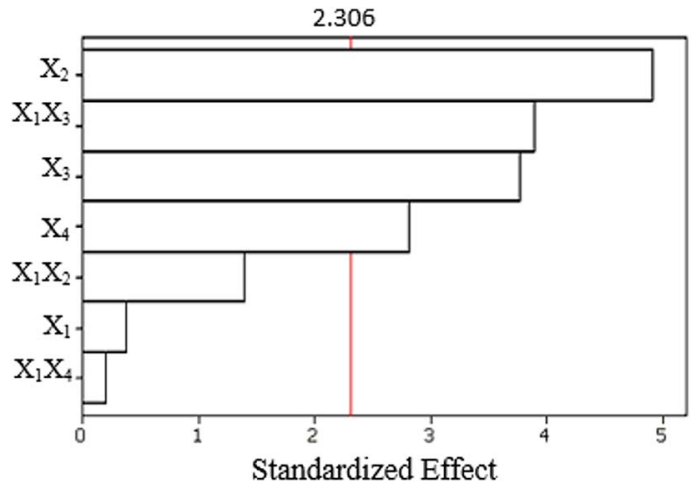

Fig. 3 Pareto chart of standardized effects (response is $Y(\%)$, and $\alpha=0.05)$.

\section{The effect of the main factors}

Fig. 4 shows the trends of the main factors. According to this plot, it could be decided which factor at which level would be effective; the mean values shown in the figure were obtained by averaging the responses over all runs. The plot shows that the response $Y$ (relative crystallinity and consequently the efficiency of the formation of zeolite) does not significantly change with an increase in $\mathrm{X}_{1}\left(\mathrm{Na}_{2} \mathrm{O} / \mathrm{SiO}_{2}\right)$. However, an increase in the $\mathrm{SiO}_{2} /$ $\mathrm{Al}_{2} \mathrm{O}_{3}$ molar ratio leads to an increase in ZSM-5 yields.

This plot shows that the highest efficiency of zeolite formation is achieved when $\mathrm{SiO}_{2} / \mathrm{Al}_{2} \mathrm{O}_{3}\left(\mathrm{X}_{2}\right), \mathrm{H}_{2} \mathrm{O} / \mathrm{SiO}_{2}\left(\mathrm{X}_{3}\right)$, and aging time $\left(\mathrm{X}_{4}\right)$ are at their highest levels.

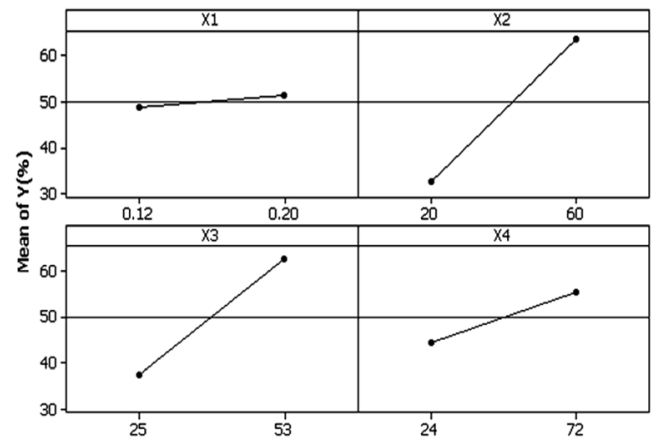

Fig. 4 Main effects plot (mean values of data) for $Y(\%)$.
Estimated regression coefficient for the response $Y$ and model validation

The $p$ values and coefficients of the polynomial model (eqn (1)) are shown in Table 5. According to Table 4, on the basis of the $p$ values, only the main factors and their interactions were effective. As shown in Table 5 , the $p$ value for main factors $\left(\mathrm{X}_{2}, \mathrm{X}_{3}\right.$, and $\mathrm{X}_{4}$ ) is less than 0.05 , but the $p$ value for $\mathrm{X}_{1}$ is higher than 0.05. This result is in agreement with the results of the Pareto chart and the table showing the analysis of variance; moreover, $\mathrm{X}_{1}$ is a non-impact factor; thus, it will be removed from the equation, and the squared values of $\mathrm{X}_{2}, \mathrm{X}_{3}$, and $\mathrm{X}_{4}$ have $p>0.05$. Therefore, they will also be removed from the equation. For the 2 -way interactions of $\mathrm{X}_{1} \mathrm{X}_{3}$, the $p$ value is less than 0.05 , and the $p$ values for $\mathrm{X}_{1} \mathrm{X}_{2}$ and $\mathrm{X}_{1} \mathrm{X}_{4}$ are higher than 0.05 . Thus, the effects of $\mathrm{X}_{1} \mathrm{X}_{2}$ and $\mathrm{X}_{1} \mathrm{X}_{4}$ on the response are ineffective, and these factors will be removed from the equation. The regression equation is defined as follows:

$$
\begin{aligned}
Y= & 47.731+13.977 \mathrm{X}_{2}+10.356 \mathrm{X}_{3}+7.744 \mathrm{X}_{4} \\
& +10.706 \mathrm{X}_{1} \mathrm{X}_{3}
\end{aligned}
$$

Fig. 5 shows the residual plots for $Y$ in the model (eqn (2)). For the validation of the proposed method, residual plots were obtained. This technique is very useful for measuring the residual distribution. As can be observed in the plot of normal distribution, the residuals of the response are randomly scattered around zero in the residual plots.

The histogram of the residuals shows that their distribution is non-uniform, and it looks like there is an outlier regarding the existence of a small bar far from the rest of the bars, and the residuals (versus order) exhibit no clear pattern.

\section{Response optimization}

If there were no significant two-way interactions, the plots of the main effects (according to Fig. 4) would sufficiently describe the best condition for the synthesis of ZSM-5, that is, $X_{1}, X_{2}, X_{3}$, and $\mathrm{X}_{4}$ should be set to the high level (1), high level (1), high level (1) and high level (1), respectively.

However, the interactions were significant (Table 4) in this experiment and could increase or decrease the effect of each factor. Therefore, the other step of the optimization should be the examination of the surface plots of $Y$. These surface plots are

Table 5 Estimated regression coefficients for $Y$ (coded units)

\begin{tabular}{lrrlrl}
\hline Term & Effect & Coef. & SE coef. & \multicolumn{1}{l}{$T$} & $P$ \\
\hline Constant & & 47.731 & 2.749 & 17.37 & 0.000 \\
$\mathrm{X}_{1}$ & -2.038 & -1.019 & 2.749 & -0.37 & 0.720 \\
$\mathrm{X}_{2}$ & 27.954 & 13.977 & 2.849 & 4.91 & 0.001 \\
$\mathrm{X}_{3}$ & 20.712 & 10.356 & 2.749 & 3.77 & 0.005 \\
$\mathrm{X}_{4}$ & 15.488 & 7.744 & 2.749 & 2.82 & 0.023 \\
$\mathrm{X}_{1} \mathrm{X}_{2}$ & 7.954 & 3.977 & 2.849 & 1.40 & 0.200 \\
$\mathrm{X}_{1} \mathrm{X}_{3}$ & 21.412 & 10.706 & 2.749 & 3.89 & 0.005 \\
$\mathrm{X}_{1} \mathrm{X}_{4}$ & 1.088 & 0.544 & 2.749 & 0.20 & 0.848
\end{tabular}



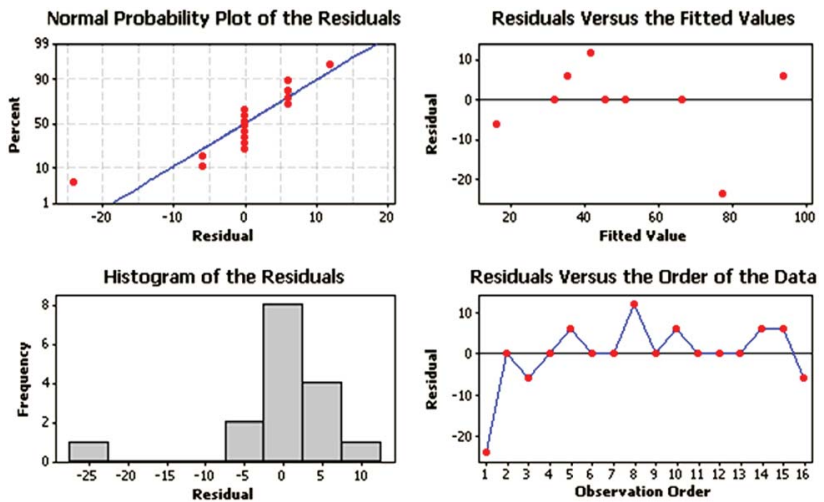

Fig. 5 Residual plots for $Y(\%)$.

three-dimensional (3D) plots that show the response as a function of two variables, whereas other variables are kept constant. These plots can provide information about the interaction of variables and are also useful for understanding the main effects and interactions. The three-dimensional plots for the response $(\%$ Y) (relative crystallinity and consequently the efficiency of the formation of zeolite) obtained from eqn (2) are shown in Fig. 6 and 7. In Fig. 6, the variables that are not in the graph are set at their low level $(-1)$, whereas in Fig. 7 , the variables that are not in the graph are set at their high level (1); Fig. 6(a) shows the surface plot of the response $\% Y$ (efficiency of the formation of zeolite) as a function of $\mathrm{X}_{1}$ and $\mathrm{X}_{2}$; Fig. 6(b) shows the surface plot of the response $\% Y$ as a function of $\mathrm{X}_{1}$ and $\mathrm{X}_{3}$; Fig. 6(c) shows the surface plot of the response $\% Y$ as a function of $X_{1}$ and $\mathrm{X}_{4}$. According to Fig. $6(\mathrm{a}-\mathrm{c})$, the highest value of $Y$ is obtained when the $\mathrm{SiO}_{2} / \mathrm{Al}_{2} \mathrm{O}_{3}, \mathrm{H}_{2} \mathrm{O} / \mathrm{SiO}_{2}$, and aging time levels are high; as shown in Fig. 7(a-c), the highest value of $Y$ is obtained when the $\mathrm{Na}_{2} \mathrm{O} / \mathrm{SiO}_{2}, \mathrm{SiO}_{2} / \mathrm{Al}_{2} \mathrm{O}_{3}, \mathrm{H}_{2} \mathrm{O} / \mathrm{SiO}_{2}$, and aging time levels are high. The response $Y$ presents the maximum value $90.30 \%$ at the optimal parameters of $X_{1}(1), X_{2}(1), X_{3}(1)$, and $\mathrm{X}_{4}(1)$. Pure ZSM- 5 can be obtained at the gel composition $\mathrm{Na}_{2} \mathrm{O}$ / $\mathrm{SiO}_{2}=0.2, \mathrm{SiO}_{2} / \mathrm{Al}_{2} \mathrm{O}_{3}=60$, and $\mathrm{H}_{2} \mathrm{O} / \mathrm{SiO}_{2}=53$, and aging time $=72 \mathrm{~h}$.

\section{Prediction and confirmation of optimum conditions}

Using the optimal conditions obtained from this method, the ZSM-5 nanocrystalline material was synthesized at $180{ }^{\circ} \mathrm{C}$ under atmospheric pressure. The typical X-ray diffraction pattern of the sample obtained under optimal conditions demonstrated the formation of the pure MFI phase. Fourier
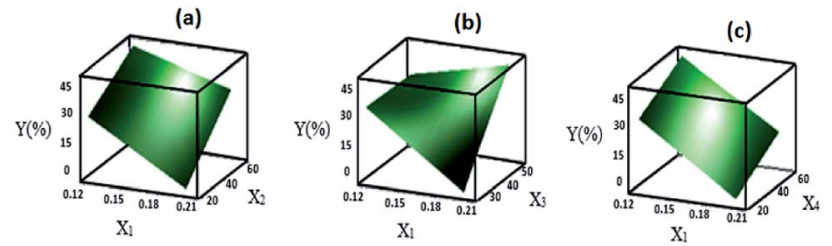

Fig. 6 Surface plots of $Y$ (variables that are not in the graph are set at their low level).
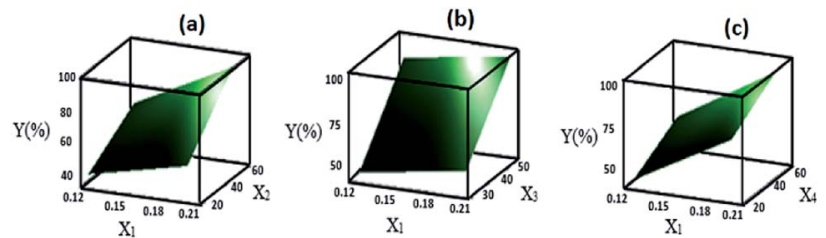

Fig. 7 Surface plots of $Y$ (variables that are not in the graph are set at their high level)

transform infrared (FTIR) absorption spectra were obtained via the $\mathrm{KBr}$ pellet technique using the Tensor 27 spectrometer in the range of $4000-400 \mathrm{~cm}^{-1}$ with the resolution of $4 \mathrm{~cm}^{-1}$. The crystal morphology and the size of the ZSM-5 powders obtained under the optimal conditions were investigated by SEM.

\section{X-ray diffraction studies}

Fig. 8 shows the XRD pattern of the zeolite obtained under optimal conditions, which is in accordance with that reported in ref. 38. The XRD pattern shows peaks in the ranges of $2 \theta=7-$ $9^{\circ}$ and $23-25^{\circ}$, which correspond to the specific peaks of the ZSM-5 zeolite. This indicates that the synthesized ZSM-5 zeolite powders are ZSM-5 zeolite crystals.

\section{Fourier-transform infrared studies}

The FTIR spectra of the nanosized ZSM-5 zeolite without organic templates are shown in Fig. 9. Fig. 9 shows an infrared band at $547 \mathrm{~cm}^{-1}$, which has been assigned to the fivemembered ring of the pentasil zeolite structure; $;^{42,43}$ the presence of the asymmetric stretching vibration band of the T-O bond (at $1225 \mathrm{~cm}^{-1}$ ) provides additional evidence for the formation of the nanosized ZSM-5 zeolite, and this band has been assigned to external linkages (between $\mathrm{TO}_{4}$ tetrahedra) and is the structure-sensitive IR band of ZSM-5 zeolite. ${ }^{44}$ The bands at $791 \mathrm{~cm}^{-1}$ and $1094 \mathrm{~cm}^{-1}$ are assigned to the external symmetric stretching and the internal asymmetric stretching

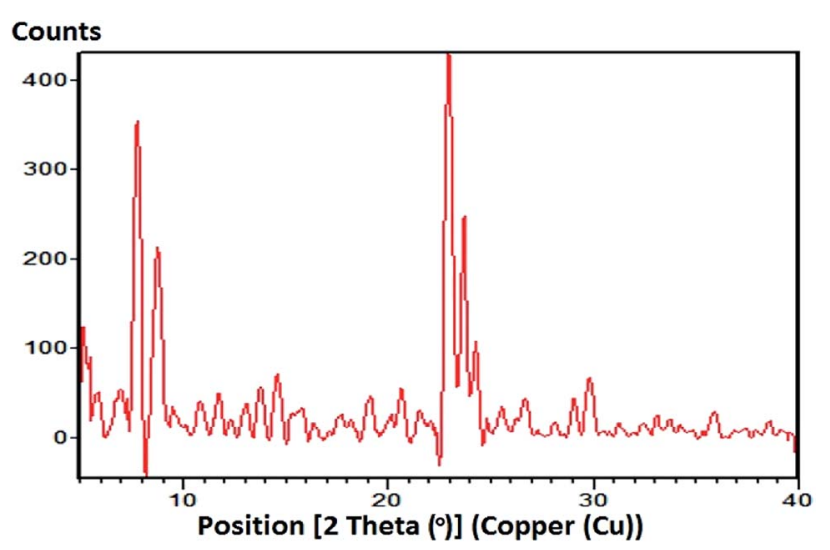

Fig. 8 XRD pattern of the nanosized ZSM-5 zeolite without organic templates. 


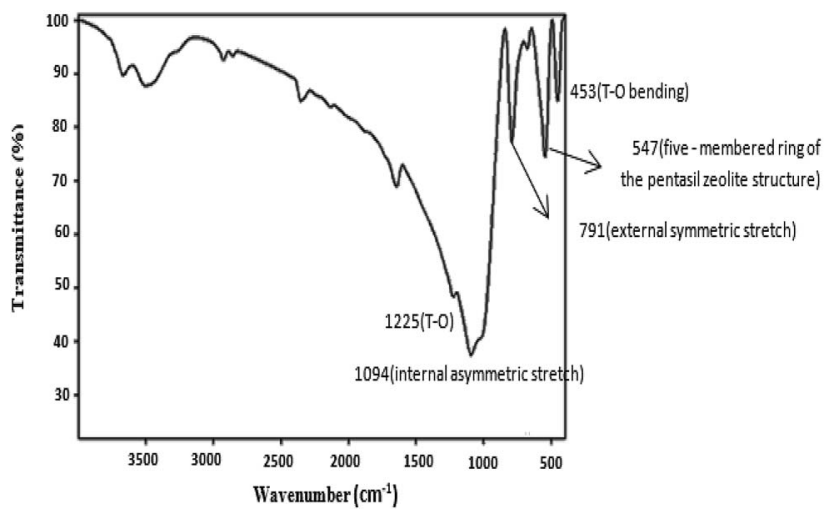

Fig. 9 FTIR spectra of the nanosized ZSM-5 zeolite without organic templates.

vibrations, respectively. The band at $453 \mathrm{~cm}^{-1}$ is assigned to the T-O bending vibration.

\section{Scanning electron microscopy studies}

The morphology of the synthesized ZSM-5 zeolite powders was investigated using SEM. Fig. 10 shows the SEM image of the sample synthesized under optimal conditions. In the SEM image (Fig. 10), hexagonal morphology, typical of the ZSM-5 zeolite, is observed.

\section{Characterization of the hybrid materials and inclusion complex}

Fourier-transform infrared studies. Fig. 11 shows the FTIR spectra of zeolite, $\beta$-CD and $\beta C D$-modified zeolite. The FTIR spectrum of CD shows characteristic peaks at $3395 \mathrm{~cm}^{-1}$ and $2928 \mathrm{~cm}^{-1}$ due to the $\mathrm{O}-\mathrm{H}$ and $\mathrm{C}-\mathrm{H}$ stretching vibrations. In addition, the peaks at $1645 \mathrm{~cm}^{-1}, 1157 \mathrm{~cm}^{-1}, 1030 \mathrm{~cm}^{-1}$, and $851 \mathrm{~cm}^{-1}$ correspond to $\mathrm{H}-\mathrm{O}-\mathrm{H}, \mathrm{C}-\mathrm{O}, \mathrm{C}-\mathrm{O}-\mathrm{C}$ glucose units and $\mathrm{C}-\mathrm{O}-\mathrm{C}$ of the rings of $\mathrm{CD}$, respectively. Fig. 11(c) shows the FTIR spectra of CD-functionalized ZSM-5 zeolite. As observed in

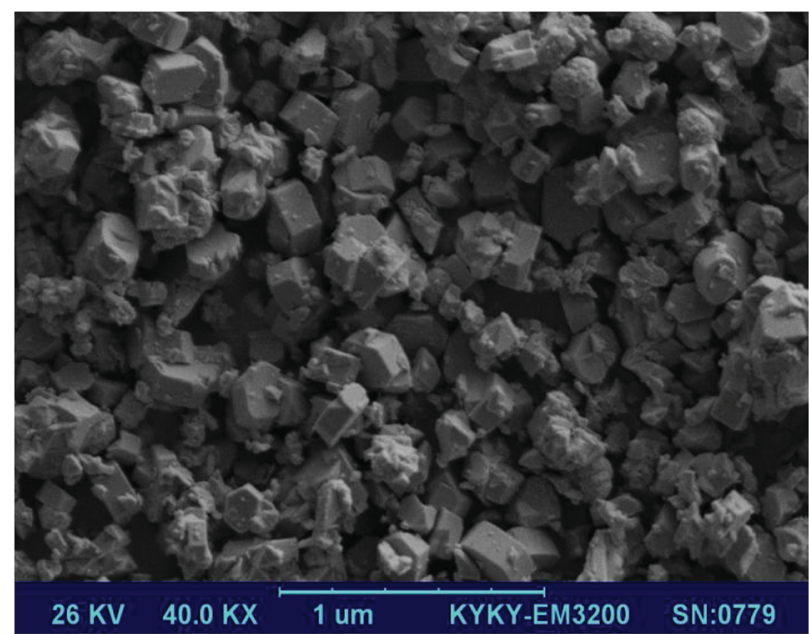

Fig. 10 An SEM image of the ZSM-5 zeolite sample synthesized under optimal conditions.

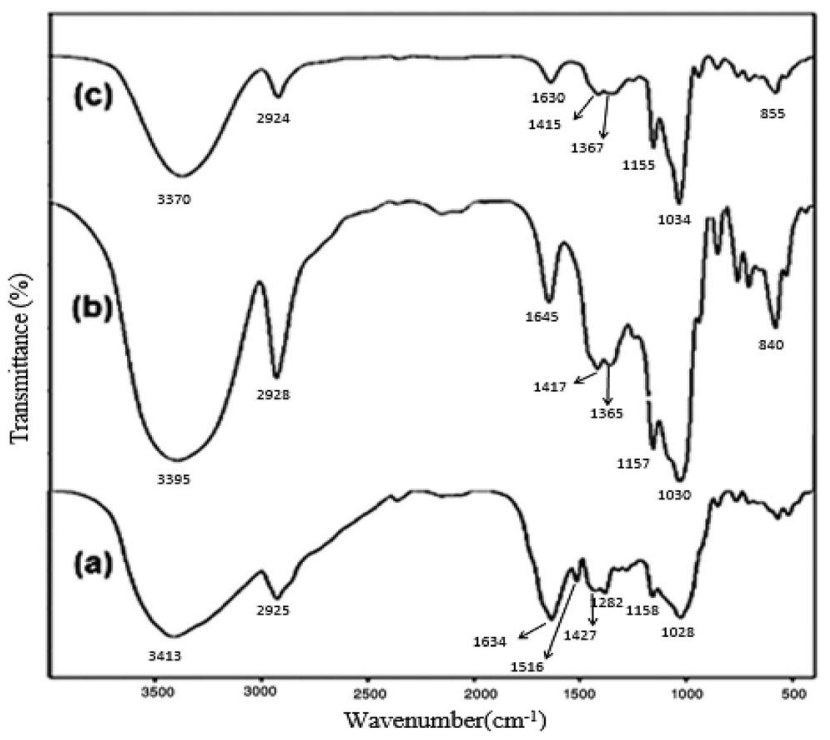

Fig. 11 FTIR spectra of (a) ZSM-5 zeolite, (b) $\beta-C D$, and (c) $\beta C D-$ modified ZSM-5.

Fig. 11(a), the spectra of CD-functionalized ZSM-5 retained most of the characteristic peaks of $\beta-C D$ and did not exhibit any of the characteristic peaks of ZSM-5. ${ }^{45}$

FTIR spectroscopy was also used to ascertain the formation of the CDZ-CUR inclusion complex. CDZ-CUR complexes prepared by methanol reflux appeared as amorphous substances whose colour was lighter than that of curcumin. Fig. 12 shows the FTIR spectra of curcumin, CDZ and the CDZCUR complex. The FTIR spectra also confirmed the CDZ-CUR complex formation. Curcumin showed a main peak at $3413 \mathrm{~cm}^{-1}$, assigned to the $\mathrm{OH}$ stretch. The bands at $1634 \mathrm{~cm}^{-1}$ were assigned to the stretching vibrations of the benzene ring of

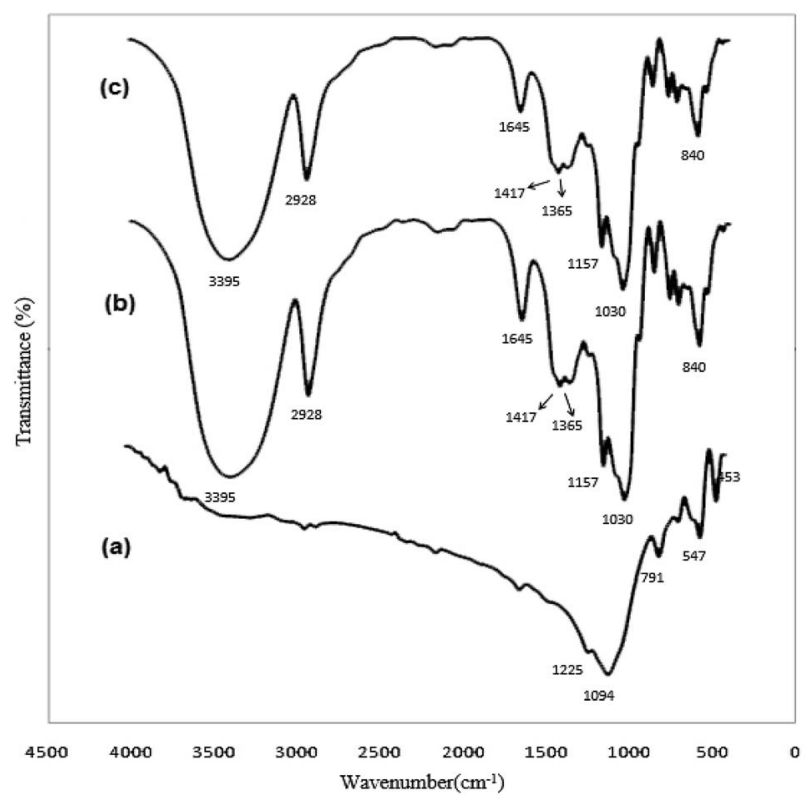

Fig. 12 FTIR spectra of (a) curcumin, (b) CDZ, and (c) CDZ-CUR. 

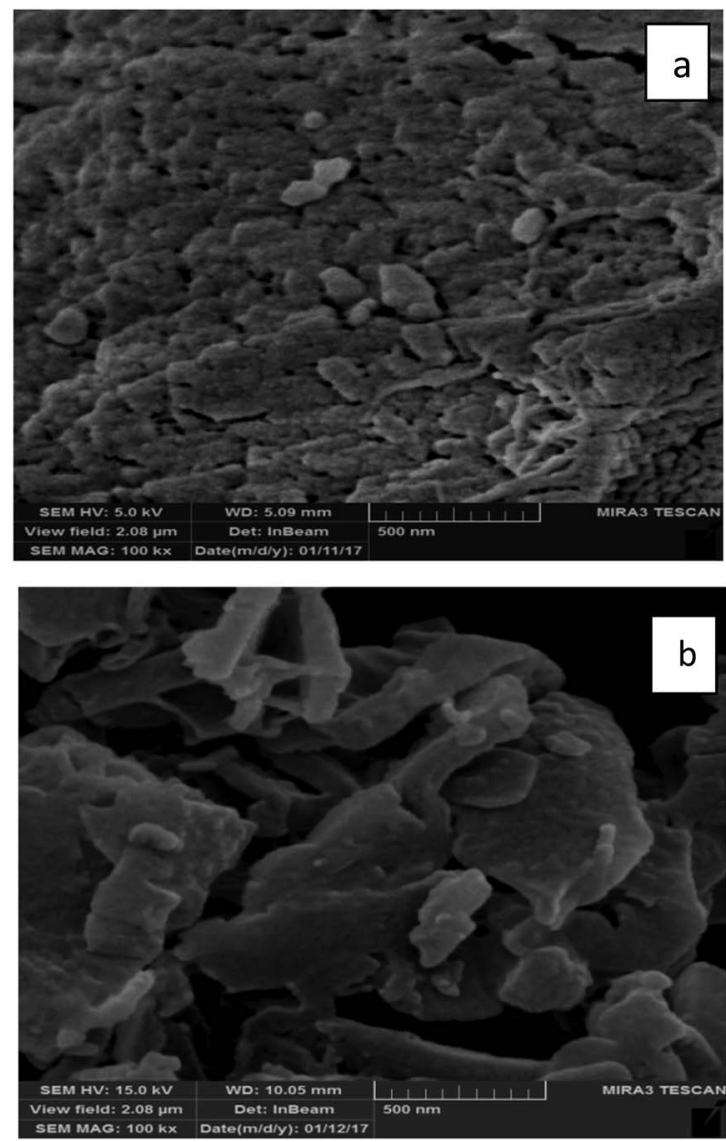

Fig. 13 FESEM images of the (a) CDZ and (b) the CDZ-CUR inclusion complex.

CUR, and those at $1516 \mathrm{~cm}^{-1}$ were assigned to the $\mathrm{C}=\mathrm{O}$ and $\mathrm{C}=\mathrm{C}$ vibrations of CUR; moreover, the bands at $1282 \mathrm{~cm}^{-1}$ were attributed to the $\mathrm{Ar}-\mathrm{O}$ stretching vibrations. The FTIR spectra of the CDZ-CUR complexes were similar to the $\beta$-CD spectrum and also contained a number of peaks related to curcumin. ${ }^{42}$

Field-emission scanning electron microscopy studies. Fig. 13(a) and (b) show the FESEM images of CDZ and CDZ-

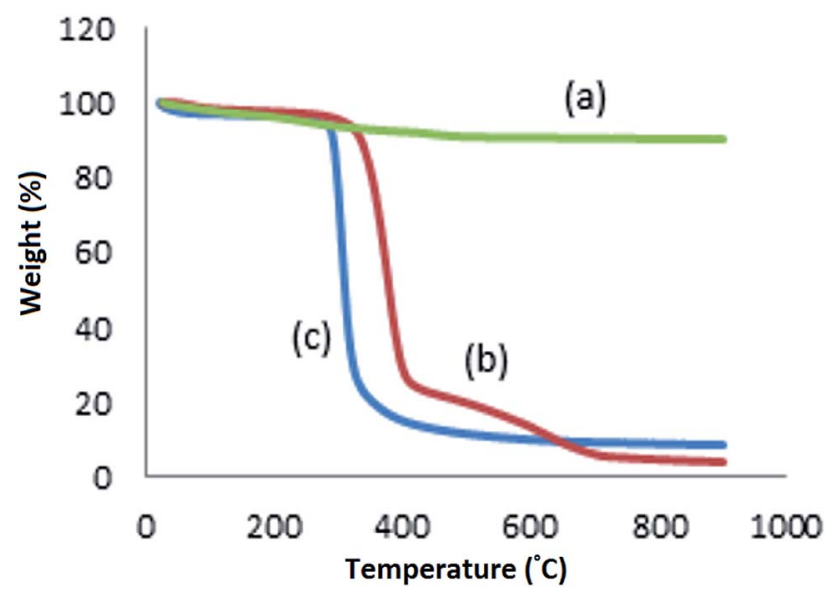

Fig. 14 Thermogravimetric curves of the (a) ZSM-5 zeolite, (b) CDZ, and the (c) CDZ-CUR inclusion complex.

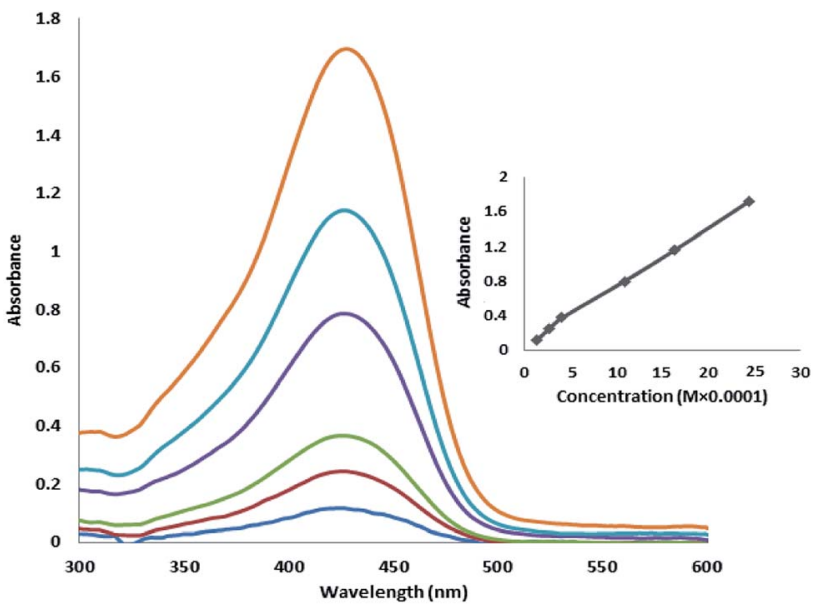

Fig. 15 Absorption spectra and the calibration curve of curcumin.

CUR, respectively. CDZ shows crystalline, bulk-like structures throughout the sample. The image of the CDZ-CUR inclusion complexes exhibits layered-like structures; this change in morphology represents the formation of the complex and placement of curcumin in the cyclodextrin cavities.

Thermogravimetric analysis (TGA). Fig. 14 shows the thermogravimetric curves of zeolite, CDZ, and CDZ-CUR. According to Fig. 14(a), the weight loss between 25 and $800{ }^{\circ} \mathrm{C}$ was $10 \%$; since nanosized zeolite was synthesized without an organic template, organic decomposition during the heating process was very low, and this low weight loss was caused by the removal of the moisture content of the samples. Fig. 14(b) shows a weight loss of about $80 \%$ at $500{ }^{\circ} \mathrm{C}$. This weight loss can be due to the destruction of the units of cyclodextrin and other organic structures. At $700{ }^{\circ} \mathrm{C}$, curcumin was degraded by only $68 \%{ }^{46}$ As observed in Fig. 14(c), the CDZ-CUR inclusion complex showed an improvement in thermal stability due to the presence of curcumin.

Absorption spectra of curcumin. To evaluate the concentration of curcumin at all the stages, such as drug absorption and release kinetics, of the experiment in this study, a calibration curve was obtained. Curcumin shows a strong absorption band

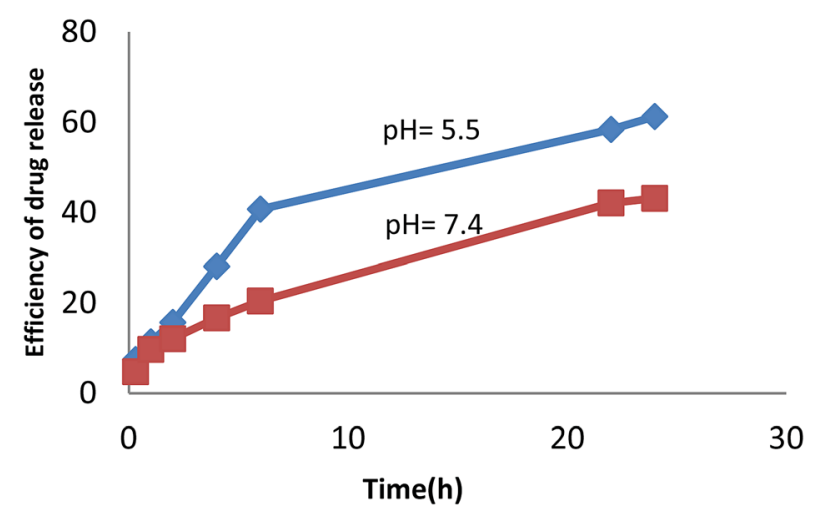

Fig. 16 Efficiency of curcumin release from CDZ-CUR in PBS $(\mathrm{pH}=$ 5.5 and 7.4 ). 
at the wavelength of $427 \mathrm{~nm}$, which can be assigned to the low energy $\pi-\pi^{*}$ excitation of curcumin. For this purpose, curcumin at different concentrations was used, and its absorption was measured at the wavelength of $427 \mathrm{~nm}$ by a UV-Vis spectrophotometer.

Fig. 15 shows the absorption spectra of curcumin. As shown in Fig. 15, with an increase in the concentration of curcumin, its absorption at the wavelength of $427 \mathrm{~nm}$ linearly increased.

In vitro drug release study. For the drug release study in $\mathrm{PBS}$ $(\mathrm{pH}=7.4$ and $\mathrm{pH}=5.5)$, the release of curcumin was measured using a standard curve of the drug at the wavelength of $427 \mathrm{~nm}$. As shown in Fig. 16, the efficiency of drug release in acidic media is much higher than that in neutral media. The efficiency of drug release was evaluated to be $43 \%$ at $\mathrm{pH}=7.4$ and $61 \%$ at $\mathrm{pH}=5.5$. This indicates that the effectiveness of the drug delivery system in a tumor tissue is higher than that in a healthy tissue.

\section{Conclusions}

In this study, a fractional factorial design method with only sixteen experiments and two runs for each of the eight experiments was used to optimize the experimental conditions for the preparation of nanosized ZSM-5 without an organic template. The effect of synthesis parameters on the efficiency of the formation of ZSM-5 zeolite was studied. Analysis of variance showed that the main effects and their two-way interactions were statistically significant $(p<0.05)$. The most important main effect was that of the $\mathrm{SiO}_{2} / \mathrm{Al}_{2} \mathrm{O}_{3}$ molar ratio, and the most important two-way interaction variable was the interaction of the $\mathrm{Na}_{2} \mathrm{O} / \mathrm{SiO}_{2}$ and $\mathrm{H}_{2} \mathrm{O} / \mathrm{SiO}_{2}$ molar ratio. It was found that $\mathrm{Na}_{2} \mathrm{O} / \mathrm{SiO}_{2}$ in the synthesis mixture had the least influence on the ZSM-5 yields. Residual plots were analyzed to validate the model. Optimized response showed that the percent of response was maximum under the optimal conditions of $\mathrm{X}_{1}(1)$, $\mathrm{X}_{2}(1), \mathrm{X}_{3}(1), \mathrm{X}_{4}(1)$. Thus, pure ZSM-5 will be achieved at the molar composition of $12 \mathrm{Na}_{2} \mathrm{O}: 60 \mathrm{SiO}_{2}: \mathrm{Al}_{2} \mathrm{O}_{3}: 3200 \mathrm{H}_{2} \mathrm{O}$. X-ray diffraction pattern, SEM and FTIR results also confirmed the formation of the sample under optimal conditions. Then, the ZSM-5 zeolite obtained under the optimum conditions was functionalized with $\beta-\mathrm{CD}$, and we demonstrated the possibility of inclusion complexation between CDZ and curcumin using a methanol reflux method. A drug delivery system based on the zeolite modified with beta cyclodextrin-containing curcumin anti-cancer drug was prepared for targeted drug delivery to cancer cells, and its effectiveness was studied under the experimental conditions. Inclusion complex formation was confirmed by FTIR spectroscopy, FESEM, UV-Vis and TGA. The results obtained in the present investigation are significant since the CDZ-CUR complexes have significantly better dissolution and can be further explored for pharmaceutical purposes. Inclusion complex formation resulted in amorphous compounds with improved solubility and dissolution of curcumin. The study of in vitro drug release showed that the efficiency of drug release under acidic conditions was higher than that under neutral conditions. Therefore, the performance of the proposed drug delivery system is higher in a tumor tissue when compared with that in a healthy tissue.

\section{Conflicts of interest}

There are no conflicts to declare.

\section{References}

1 M. Gindy and R. Prudhomme, Expert Opin. Drug Delivery, 2009, 6, 865.

2 K. Coti, M. Belowich, M. Liong, M. Ambrogio, Y. Lau, H. Khatib, J. Zink, N. Khashab and J. Stoddart, Nanoscale, 2009, 1, 16.

3 M. Danilczuk, K. Dlugopolska, T. Ruman and D. Pogocki, Mini-Rev. Med. Chem., 2008, 8, 1407.

4 D. Fatouros, D. Douroumis, V. Nikolakis, S. Ntais, A. Moschovi, V. Trivedi, B. Khima, M. Roldo, H. Nazar and P. Cox, J. Mater. Chem., 2011, 21, 7789.

$5 \mathrm{H}$. Bekkum, E. Flanigen,P. Jacobs and J. Jansen, Introduction to Zeolite Science and Practice, Elsevier Science, Amsterdam, Netherlands, 2001.

6 A. Corma, V. Fornes and F. Rey, Adv. Mater., 2002, 14, 71.

7 C. Platas-Iglesias, L. Vander Elst, W. Zhou, R. Muller, C. Geraldes, T. Maschmeyer and J. Peters, Chem.-Eur. J., 2002, 8, 5121.

8 M. Norek, I. Neves and J. Peters, Inorg. Chem., 2007, 46, 6190.

9 M. Tsotsalas, K. Kopka, G. Luppi, S. Wagner, M. Law, M. Schafers and L. De Cola, ACS Nano, 2010, 4, 342.

10 N. Ndiege, R. Raidoo, M. Schultz and S. Larsen, Langmuir, 2011, 27, 2904.

11 H. Zhang, Y. Kim and P. Dutta, Microporous Mesoporous Mater., 2006, 88, 312.

12 M. Arruebo, R. Fernandez-Pacheco, S. Irusta, J. Arbiol, M. Ibarra and J. Santamaria, Nanotechnology, 2006, 17, 4057.

13 I. Braschi, G. Gatti, G. Paul, C. Gessa, M. Cossi and L. Marchese, Langmuir, 2010, 26, 9524.

14 I. Braschi, S. Blasioli, L. Gigli, C. Gessa, A. Alberti and A. Martucci, J. Hazard. Mater., 2010, 178, 218.

15 A. Martucci, L. Pasti, N. Marchetti, A. Cavazzini, F. Dondi and A. Alberti, Microporous Mesoporous Mater., 2012, 148, 174.

16 G. Bar-Sela, R. Epelbaum and M. Schaffer, Curr. Med. Chem., 2010, 17, 190.

17 J. Jurenka, Altern. Med. Rev., 2009, 14, 141.

18 R. Maheshwari, A. Singh, J. Gaddipati and R. Srimal, Life Sci., 2006, 78, 2081.

19 A. Strimpakos and R. Sharma, Antioxid. Redox Signaling, 2008, 10, 511.

20 R. Sharma, W. Steward and A. Gescher, Adv. Exp. Med. Biol., 2007, 595, 453.

21 Y. Wang, M. Pan, A. Cheng, L. Lin, Y. Ho, C. Hsieh and J. Lin, J. Pharm. Biomed. Anal., 1997, 15, 1867.

22 P. Anand, A. B. Kunnumakkara, R. A. Newman and B. B. Aggarwal, Mol. Pharm., 2007, 4, 807.

23 S. Bisht, G. Feldmann, S. Soni, R. Ravi, C. Karikar, A. Maitra and A. Maitra, J. Nanobiotechnol., 2007, 5, 3. 
24 J. Shaikh, D. D. Ankola, V. Beniwal, D. Singh and M. N. Kumar, Eur. J. Pharm. Sci., 2009, 37, 223.

25 H. Tonnesen, Pharmazie, 2002, 57, 820.

26 Z. Wang, M. Leung, T. Kee and D. English, Langmuir, 2010, 26, 5520 .

27 M. Leung and T. Kee, Langmuir, 2009, 25, 5773.

$28 \mathrm{H}$. Ingolfsson, R. Koeppe and O. Andersen, Biochemistry, 2007, 46, 10384.

29 K. Maiti, K. Mukherjee, A. Gantait, B. P. Saha and P. K. Mukherjee, Int. J. Pharm., 2007, 330, 155.

30 A. Safavy, K. Raisch, S. Mantena, L. Sanford, S. Sham, N. Krishna and J. Bonner, J. Med. Chem., 2007, 50, 6284.

31 G. Horvath, T. Premkumar, A. Boztas, E. Lee, S. Jon and K. E. Geckeler, Mol. Pharm., 2008, 5, 358.

32 Q. Wu, X. Meng, X. Gao and F. Xiao, Acc. Chem. Res., 2018, 51, 1396.

33 H. Li, X. Liu, S. Qi, L. Xu, G. Shi, Y. Ding, X. Yan, Y. Huang and J. Geng, Angew. Chem., Int. Ed., 2017, 56, 14090.

34 K. Dey, S. Ghosh and M. Naskar, Ceram. Int., 2013, 39, 2153.

35 D. Hu, Q. Xia, X. Lu, X. Luo and Z. Liu, Mater. Res. Bull., 2008, 43, 3553.
36 D. Zhang, R. Wang and X. Yang, Microporous Mesoporous Mater., 2009, 126, 8.

37 D. Hu, Q. Xia, X. Lu, X. Luo and Z. Liu, Mater. Res. Bull., 2008, 43, 3553.

38 Y. Cheng, L. Wang, J. Li, Y. Yang and X. Sun, Mater. Lett., 2005, 59, 3427.

39 M. Khanmohammadi, Sh. Amani and A. Bagheri Garmarudi, Anal. Methods, 2016, 8, 2799.

40 A. Szarpak-Jankowska, C. Burgess, L. De Cola and J. Huskens, Chem.-Eur. J., 2013, 19, 14925.

41 B. Tang, L. Ma, H. Wang and G. Zhang, J. Agric. Food Chem., 2002, 50, 1355.

42 S. Karmakar, N. Banik, S. Patel and S. Ray, Neurosci. Lett., 2006, 407, 53.

43 S. Shishodia, H. Amin, R. Lai and B. Aggarwal, Biochem. Pharmacol., 2005, 70, 700.

44 G. Sa and T. Das, Cell Div., 2008, 3, 14.

45 I. Mallard, L. Stade, S. Ruellan, P. Jacobsen, K. Larsen and S. Fourmentin, Colloids Surf., A, 2015, 482, 50.

46 M. Yallapu, M. Jaggi and S. Chauhan, Colloids Surf., B, 2010, 79, 113. 